\title{
Correction to: A systematic review of internet-based information for individuals with Raynaud's phenomenon and patients with systemic sclerosis
}

\author{
Vikrant Devgire $^{1} \cdot$ Andreas Flores Martin $^{1} \cdot$ Lorraine McKenzie $^{2} \cdot$ Robert D. Sandler $^{1} \cdot$ Michael Hughes $^{1,3}$ (D)
}

Published online: 11 May 2020

(C) International League of Associations for Rheumatology (ILAR) 2020

\section{Correction to: Clinical Rheumatology} https://doi.org/10.1007/s10067-020-05023-5

The authors have identified an error in their manuscript and have incorrectly referred to the overall DISCERN score for SSc and RP as 2.21 and 1.99, respectively, in the abstract and discussion. The correct DISCERN quality scores are listed in Table 2.

Publisher's note Springer Nature remains neutral with regard to jurisdictional claims in published maps and institutional affiliations.

The online version of the original article can be found at https://doi.org/ $10.1007 / \mathrm{s} 10067-020-05023-5$

Michael Hughes

Michael.hughes-6@postgrad.manchester.ac.uk

1 Department of Rheumatology, Royal Hallamshire Hospital, Sheffield Teaching Hospitals NHS Foundation Trust, Sheffield S10 2JF, UK

2 Centre for Musculoskeletal Research, The University of Manchester, Manchester, UK

3 Centre for Musculoskeletal Research, Faculty of Biology, Medicine and Health, The University of Manchester, Manchester, UK 